\title{
Dietary potential renal acid load and net acid excretion in rural and urban pre-menopausal Gambian women
}

\author{
G.R. Goldberg ${ }^{1,2}$, S.E. Dalzell ${ }^{1}$, L.M.A. Jarjou ${ }^{2}$, K. Ward ${ }^{1}$ and A. Prentice ${ }^{1,2}$ \\ ${ }^{1}$ Medical Research Council Elsie Widdowson Laboratory, Cambridge CBI 9NL, UK and \\ ${ }^{2}$ Medical Research Council Unit The Gambia, The Gambia
}

The role that diet plays in acid-base homeostasis, particularly through effects on the skeleton, has been the focus of much research ${ }^{(1)}$. Measured or predicted Potential Renal Acid Load (PRAL) and net acid excretion (NAE) expressed as milli equivalents (mEq) have been associated with bone mineral and markers of bone metabolism in adults and children ${ }^{(2,3)}$. In particular positive effects of diets high in fruits and vegetables, leading to a lower PRAL or NAE have been highlighted. These studies have been conducted in Western populations and to our knowledge none have been reported in African populations. We report here some preliminary findings from a study conducted in rural ( $n$ 75) and urban ( $n$ 58) Gambian women (Dalzell et al. unpublished results). Prospective 2-day weighed records were made and the data coded and analysed using Gambian Food Composition Tables ${ }^{(4)}$ and an integrated dietary assessment system $^{(5)}$. Reported intakes of protein, phosphorus, potassium, magnesium and calcium were used to calculate PRAL, protein:potassium ratio, and estimated NAE (NAE $\mathrm{ES}$ ) using the formulae derived by Remer et $a l^{(2)}$ and Frassetto et $a l^{(3)}$. Values were not adjusted for energy. Results are shown in the Table. Data were analysed by ANOVA and Scheffe's post hoc tests.

\begin{tabular}{|c|c|c|c|c|c|c|}
\hline & \multicolumn{3}{|c|}{ Rural women } & \multicolumn{3}{|c|}{ Urban women } \\
\hline & Mean & SD & Range & Mean & SD & Range \\
\hline PRAL (mEq/day) & $-9 \cdot 3$ & 11.7 & $-46 \cdot 5$ & 1.1 & $7 \cdot 0$ & $-14.4-17$ \\
\hline $\mathbf{N A E}_{\mathrm{E}}$ & $29 \cdot 2$ & $12 \cdot 2$ & $-12 \cdot 7-56 \cdot 1$ & $42 \cdot 7$ & 8.3 & $25 \cdot 6-70$ \\
\hline $\begin{array}{l}\text { Protein:potassium } \\
(\mathrm{g} / \mathrm{mEq})\end{array}$ & $1 \cdot 2$ & $0 \cdot 2$ & $0 \cdot 5-1 \cdot 7$ & 1.4 & 0.2 & 0.9 \\
\hline $\begin{array}{l}\text { Renal net acid } \\
\text { excretion ( }(\mathrm{EEq} / \mathrm{day})\end{array}$ & 53.9 & $13 \cdot 7$ & $19 \cdot 2-82 \cdot 0$ & 68.5 & 11.5 & 3 \\
\hline
\end{tabular}

These values are lower than reported in women from the US and Europe. The differences between the rural and urban women were significant (all $P<0.0001$ ) and consistent with the observations that the rural group ate more fruit and green leafy vegetables, and the urban group ate more fish (Dalzell et al. unpublished results). The nutrition transition is likely to underlie these differences. Analyses are ongoing to investigate relationships with DXA measurements of whole-body, hip and spine bone mineral, and with urinary measures.

\section{Acknowledgements}

Supported by the UK Medical Research Council (MRC) under programmes U105960371 and U123261351. This research is jointly funded by the MRC and the Department for International Development (DFID) under the MRC/DFID Concordat agreement. SD is in receipt of an MRC $\mathrm{PhD}$ studentship.

1. New SA (2002) Proc Nutr Soc 61, 151-164.

2. Remer T, Dimitriou T, Manz F (2003) Am J Clin Nutr 77, 1255-1260.

3. Frassetto LA, Todd KM, Morris RC Jr et al. (1998) Am J Clin Nutr 68, 576-583.

4. Prynne CJ, Paul AA (2011) Food composition table for use in The Gambia. MRC Human Nutrition Research, Cambridge.

5. Fitt E, Cole D, Ziauddeen N et al. (2015) Public Health Nutr 18, 234-241. 